\section{Protecting retinal ganglion cells}

${ }^{1}$ Department of Clinical Neurosciences, John van Geest Centre for Brain Repair, University of Cambridge, Cambridge, UK

2Eye Department, Addenbrooke's Hospital, Cambridge, UK

${ }^{3}$ Cambridge NIHR Biomedical Research Centre, Cambridge, UK

${ }^{4}$ Wellcome Trust-MRC Cambridge Stem Cell Institute, University of Cambridge, Cambridge, UK

Correspondence: KR Martin, John van Geest Centre for Brain Repair, University of Cambridge, Forvie Site, Robinson Way, Cambridge CB2 OPY, UK Tel: +44 (0)1223 216427 Fax: +44 (0)1223 331174 E-mail: krgm2@cam.ac.uk

Received: 11 October 2016 Accepted in revised form: 26 November 2016 Published online: 13 January 2017

\begin{abstract}
Retinal ganglion cell degeneration underlies several conditions which give rise to significant visual compromise, including glaucoma, hereditary optic neuropathies, ischaemic optic neuropathies, and demyelinating disease. In this review, we discuss the emerging strategies for neuroprotection specifically in the context of glaucoma, including pharmacological neuroprotection, mesenchymal stem cells, and gene therapy approaches. We highlight potential pitfalls that need to be considered when developing these strategies and outline future directions, including the prospects for clinical trials.

Eye (2017) 31, 218-224; doi:10.1038/eye.2016.299; published online 13 January 2017
\end{abstract}

\section{Introduction}

Retinal ganglion cells (RGCs) provide the final common pathway to transmit all visual information processed by the retina to the brain. RGC degeneration therefore has a significant visual impact and is the leading cause of irreversible blindness worldwide. ${ }^{1}$ There are unmet clinical needs for many conditions affected by RGC degeneration including glaucoma, hereditary optic neuropathies, ischaemic optic neuropathies and demyelinating disease.

Lowering intraocular pressure (IOP) reduces the risk of progressive RGC loss in glaucoma but no currently available treatments directly prevent RGC damage. However, recent successes in the treatment of other progressive retinal pathologies have paved the way for the advancement of several strategies to target RGC degeneration. In this review, we outline the ongoing clinical need to develop approaches to protect RGCs specifically in the context of glaucoma and discuss emerging strategies (Figure 1) that show promise, potential pitfalls and future directions including the prospects for clinical trials of neuroprotective treatments.
The clinical need for neuroprotection

Raised IOP is the strongest risk factor for glaucoma ${ }^{2,3}$ and all current therapeutic strategies work by lowering the IOP either medically or surgically. IOP lowering is a powerful, welltolerated approach for many patients but the clinical need for additional strategies remains as a proportion of patients continue to progress despite effective IOP reduction. Even in populations with access to the best treatments currently available, an estimated one in eight patients will still eventually become blind in at least one eye due to glaucoma progression. 4,5

The precise pathogenesis underlying glaucoma progression is not fully understood but glaucoma is now considered to be a heterogeneous group of conditions giving rise to RGC damage. Differing underlying aetiologies contribute to the glaucoma phenotype with vascular, mitochondrial or connective tissue pathology likely to be involved to varying extents in different individuals. While effective neuroprotection strategies may not always require full knowledge of the primary degeneration process, the potential does exist for the development of individualised treatments according to the relative contributions of the various disease processes in individual patients. For example, myopic patients or those with connective tissue disorders who are theoretically more susceptible to RGC damage from IOP fluctuations due to a thinner lamina cribrosa and altered scleral elasticity may be less likely to respond to interventions that improve vascular dysregulation or mitochondrial function than those identified to have predominantly other pathologies on genetic testing. Individuals may also have a number of different genetic predispositions to develop glaucoma but with advances in gene editing technology, for example with the CRISPR/Cas9 system recently having been used to partially restore visual function in blind rodents, ${ }^{6}$ perhaps it is only a matter of time before glaucoma patients will be 
able to receive targeted treatments to overcome their innate susceptibility to the disease.

The ability to confer additional neuroprotection early to those deemed to be at highest lifetime risk may also prove to be beneficial and treatments that ultimately restore visual function to those at an advanced stage of the disease process remains an ambitious but important goal.

\section{Neuroprotective strategies}

Neuroprotection aims to augment the benefit provided by IOP lowering in order to slow the rate of RGC cell death and preserving the remaining level of vision. Whether any potential neuroprotective strategies can also improve the function of injured retinal ganglion cells remains to be seen. Neuroregenerative approaches are a key target of the National Eye Institute Audacious Goals Initiative. Regeneration of the optic nerve has recently been shown to restore some visual function in animal models ${ }^{7}$ and there is a compelling argument for a combined neuroprotective/neuroregenerative approach when considering future treatment strategies for glaucoma. Neuroregeneration of RGCs has been extensively reviewed elsewhere ${ }^{8-10}$ and is discussed in detail in several other papers from the Cambridge Ophthalmological Symposium 2016, published in this edition of Eye.

\section{Pharmacological neuroprotection}

A number of compounds targeting a variety of mechanisms including modulation of glutamate-induced excitotoxicity, ${ }^{11-14}$ vascular regulation via inhibition of nitric oxide synthase $\mathrm{e}^{15,16}$ or the endothelin pathway, ${ }^{17,18}$ oxidative stress, ${ }^{19-23}$ and inhibition of glial activity ${ }^{24,25}$ have been shown to be neuroprotective in animal models of glaucoma though few have been tested in formal clinical trials.

Laboratory studies have demonstrated that systemic administration of brimonidine provides RGC neuroprotection in animal glaucoma models independent of its effect on IOP. ${ }^{26,27}$ This neuroprotective effect is thought to be mediated via a variety of mechanisms including brain derived neurotrophic factor (BDNF) and basic fibroblast growth factor upregulation, ${ }^{28,29}$ the activation of cell survival signalling pathways and prevention of apoptosis ${ }^{30}$ and $\alpha 2$ modulation of N-methyl-D-aspartate (NMDA) receptor function. ${ }^{31}$

In human clinical trials, brimonidine monotherapy lowered the incidence of visual field progression compared to timolol treated patients (9 vs 30\%) in the Low Pressure Glaucoma Study Group ${ }^{32}$ over a period of 30 months in patients who were able to tolerate the treatment. In addition, brimonidine administered topically twice a day for 2 weeks prior to vitrectomy achieved $2 \mathrm{nM}$ in the vitreous ${ }^{33}$ which was at a sufficient concentration for neuroprotection in previous animal studies. ${ }^{34}$ However, the repeated administration of topical agents is associated with side effects and non-compliance and therefore other approaches may have additional value.

Memantine is a non-competitive NMDA receptor antagonist which is used in the treatment of moderate to severe Alzheimer's disease and showed promising results in a monkey model of glaucoma. ${ }^{35}$ However, in large scale multicentre, randomised double-masked placebocontrolled Phase III clinical trials ${ }^{36,37}$ conducted to test the efficacy of oral memantine for glaucoma, there was no evidence of any statistical benefit compared to placebo in reducing visual field progression. The failure to demonstrate statistical significance relative to placebo in trials that took nearly 5 years at an estimated cost of over $\$ 100$ million highlighted a need for better glaucoma clinical trial design and more effective use of relevant endpoints as required by regulatory agencies.

Demonstrating that agents which have achieved neuroprotection in animal models have translational potential in human clinical trials presents several major challenges. First, accurately modelling a variable and complex multifactorial disease process such as glaucoma, where the underlying pathology is not fully understood, is difficult. Available animal models replicate some aspects of the disease but all have significant limitations. As an example, many glaucoma models involve induced elevation of IOP but do not model the increased susceptibility to glaucomatous damage that may be a contributing factor in many glaucoma patients.

Second, the way glaucoma is conventionally phenotyped is relatively unsophisticated and it is likely that different mechanisms are relevant to varying extents in different patients in ways that are not modelled effectively in animals at present.

Third, differences in outcome measures used when assessing laboratory studies and human patients are another potential issue. In addition, neuroprotective agents are often administered prior to the onset of damage in animal studies which limits their relevance when comparing any effect to therapeutic intervention in patients who already have the disease.

Slow progression of glaucoma in patients recruited to clinical trials of neuroprotection would suggest lengthy trials would be required and the individual variability that occurs when performing functional tests would be expected to necessitate large group sizes to determine whether there is evidence of any therapeutic effect.

It is therefore of considerable interest that recently, the UK Glaucoma Treatment Study (UKGTS), ${ }^{38}$ which 
evaluated vision preservation in patients taking the prostaglandin analogue Latanoprost for open-angle glaucoma in a randomised, multicentre, placebocontrolled trial demonstrated statistically significant differences between treatment groups in only one year with approximately 250 patients per group. It is conceivable that recruitment of patients progressing at a pre-defined rate prior to trial entry and enhancement of functional endpoints by clustering of measurements at the beginning and the end of studies could help to shorten neuroprotection trials and reduce the group sizes required still further.

\section{Mesenchymal stem cells}

Mesenchymal stem cells (MSCs) have been shown to be strongly neuroprotective in models of Parkinson's disease, multiple sclerosis and spinal cord injury as well as many other disease models. Over 200 clinical trials using MSCs have been registered in the NIH database with 8 trials in multiple sclerosis alone. Advantages of MSCs compared to other types of stem cells include the fact that they are easy to obtain from a variety of sources including adult bone marrow, avoid ethical concerns and can be used without immune suppression.

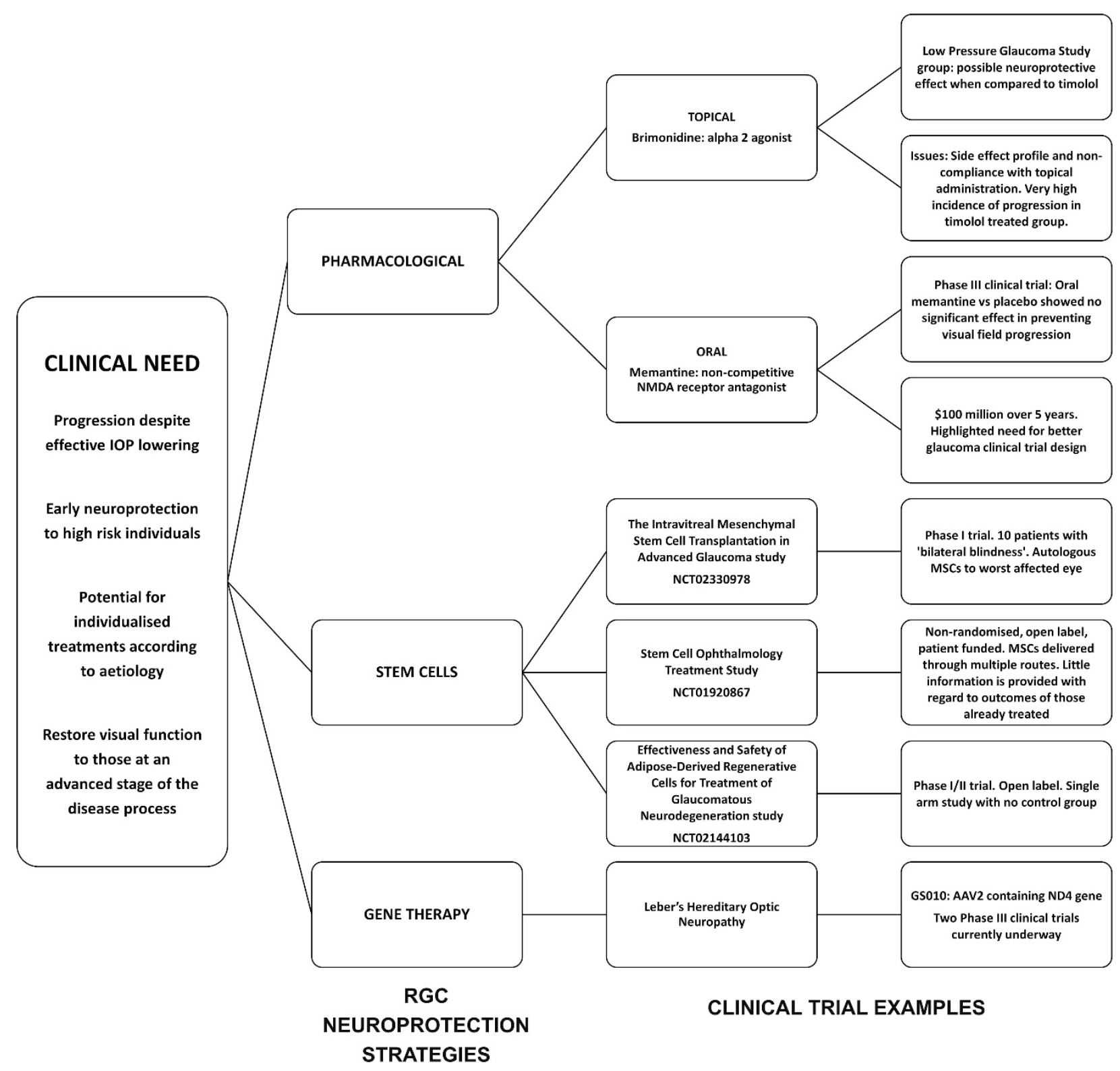

Figure 1 Summary of retinal ganglion cell (RGC) neuroprotection strategies. 
MSCs have also been shown to be neuroprotective in a rat glaucoma model. ${ }^{39-42}$ An analysis of the protective factors produced by MSCs strongly implicated plateletderived growth factor (PDGF) and subsequent blockage of PDGF signalling prevents MSC-mediated neuroprotection in animal models. ${ }^{43}$ We have also recently demonstrated a dose dependent protection against apoptosis with PDGF treatment with greater protection from MSCs in human post mortem retinal tissue (unpublished data). However, despite these encouraging results, it should be noted that PDGF and MSCs can induce reactive gliosis ${ }^{44}$ in retinal Muller cells and astrocytes with upregulation of intermediate filament proteins and retinal folding. ${ }^{44}$ Analysis of gene expression data obtained through microarray experiments suggest that both the STAT3 pathway and Lipocalin-2 (Lcn2) expression are upregulated in the presence of MSCs. This is consistent with increasing evidence that Lcn2 is involved in astrogliosis, neuroinflammation and reactive glia-mediated neurotoxicity in animal models of neurodegeneration, ${ }^{45}$ perhaps through chemokine upregulation $^{46}$ and the promotion of glial migration.

There have been similar recent reports of proinflammatory vitreous clumping of MSCs injected intravitreally ${ }^{47}$ as well as thick epiretinal membrane formation following MSC administration in humans. ${ }^{48}$ These adverse effects may also be due in part to the inconsistency in MSC isolation and preparation. An attempt to standardise the identification of these cells led to the development of the International Society for Cellular Therapy criteria ${ }^{49}$ but problems continue to be reported despite this and may limit the degree to which MSCs can successfully be used to confer neuroprotection to RGCs.

\section{Stem cells in glaucoma clinical trials}

Although there are significant concerns with regard to the unregulated use of MSCs in various centres around the world, there are currently at least three registered clinical trials evaluating the use of stem cells in glaucoma:

1. The Intravitreal Mesenchymal Stem Cell Transplantation in Advanced Glaucoma study: $:^{50}$ a Phase 1 safety study in 10 patients who meet the legal definition of bilateral blindness, with intravitreal injection of autologous MSCs administered to the worst-affected eye. Outcome measures include visual acuity, visual fields, optical coherence tomography and electroretinography.

2. Stem Cell Ophthalmology Treatment Study (SCOTS): ${ }^{51}$ a non-randomised, open-label efficacy study evaluating the use of MSCs in multiple eye diseases including glaucoma delivered through either the sub-Tenon's, retrobulbar or intravenous route. The study is patient funded and claims to be associated with a risk of potential complications of $0.0008-5 \%$ depending on the physician-selected treatment protocol chosen for individual patients. The study website declares that it hopes for visual improvement in the vast majority of individuals enrolled, but very little information is provided with regard to outcomes of those already treated.

3. Effectiveness and Safety of Adipose-Derived Regenerative Cells for Treatment of Glaucomatous Neurodegeneration study: ${ }^{52}$ an open-label safety and efficacy study in Russia. Stem cells are delivered via the subTenon's route with structural and functional endpoints and is a single-arm study with no control group.

It remains conceivable that stem cells do have the potential to provide a useful treatment strategy for glaucoma, either by a neuroprotective or neuroregenerative mechanism. However, in order to assess such strategies we need randomised, masked, controlled clinical trials and further work on the optimal mode of delivery. Most 'stem cell' treatments for glaucoma administered worldwide are unregulated and currently most registered trials are patient funded, openlabel studies. Care needs to be taken to prevent the exploitation of vulnerable patients and false promise of success with unproven treatments.

\section{Gene therapy}

There has been significant progress in the use of retinal gene replacement strategies designed to augment loss of function mutations in conditions such as Leber's congenital amaurosis and choroideraemia, with encouraging safety and efficacy results and reports of some possible improvement in visual function in some patients. ${ }^{53,54}$

Advances are also being made in RGC disease and clinical trials are currently being conducted to evaluate the efficacy of GS010, an adeno-associated virus type 2 (AAV2) construct containing the human wild-type NADH dehydrogenase subunit 4 (ND4) gene to treat patients with Leber's Hereditary Optic Neuropathy due to the G11778A ND4 mitochondrial mutation.

Preliminary data from the Phase I/II trial ${ }^{55,56}$ showed promising results and provided the foundation for two Phase III clinical trials which are currently underway. ${ }^{57,58}$

Additional gene-based strategies being investigated include the delivery of genes encoding therapeutic proteins such as neurotrophic factors. AAV2 mediated delivery of $\mathrm{BDNF}^{59}$ and ciliary neurotrophic factor 
$(\mathrm{CNTF})^{60}$ have been shown to confer RGC neuroprotection in experimental glaucoma.

Furthermore, optogenetic approaches to transform light-naïve retinal cells such as RGCs and introduce additional light sensitivity to the retina where the rod and cone photoreceptors have degenerated are also being developed. RetroSense Therapeutics are currently recruiting for a Phase I/II trial to test the safety profile of intravitreal RST-001, which delivers a gene encoding channelrhodopsin-2 to RGCs. Channelrhodopsin-2 depolarises when expressed and exposed to light, thereby generating a signal for transmission along RGC axons to the brain.

\section{Neuroprotection and the future}

The delivery of intravitreal agents has revolutionised the treatment of retinal conditions such as age related macular degeneration, diabetic retinopathy and retinal vascular pathologies and their success and widespread therapeutic use demonstrates that patients are able to tolerate intravitreal injections repeatedly. There remains a strong clinical need for RGC neuroprotection with gene therapy and cell-based therapies showing considerable promise. As we continue to develop these strategies, the need to ensure that vulnerable patients are not taken advantage of with the false promise of success from unregulated trials that rely on patient funding is paramount. Refinement of clinical trial design to ensure that endpoints are feasible and clear also remains a priority.

\section{Conflict of interest}

KRM is a consultant to Quethera Ltd. TZK declares no conflict of interest.

\section{Acknowledgements}

This work was supported by grants from Fight for Sight, Addenbrooke's Charitable Trust, the HB Allen Charitable Trust, the Cambridge Eye Trust and the Jukes Glaucoma Research Fund.

\section{References}

1 Quigley HA, Broman AT. The number of people with glaucoma worldwide in 2010 and 2020. Br J Ophthalmol 2006; 90: $262-267$.

2 Leske MC, Heijl A, Hyman L, Bengtsson B, Dong L, Yang Z. Predictors of long-term progression in the early manifest glaucoma trial. Ophthalmology 2007; 114(11): 1965-1972.

3 Friedman DS, Wilson MR, Liebmann JM, Fechtner RD, Weinreb RN. An evidence-based assessment of risk factors for the progression of ocular hypertension and glaucoma. Am J Ophthalmol 2004; 138(3 Suppl.): S19-S31.

4 Peters D, Bengtsson B, Heijl A. Lifetime risk of blindness in open-angle glaucoma. Am J Ophthalmol 2013; 156(4): 724-730.

5 Malihi M, Moura Filho ER, Hodge DO, Sit AJ. Long-term trends in glaucoma-related blindness in Olmsted County, Minnesota. Ophthalmology 2014; 121(1): 134-141.

6 Suzuki K, Tsunekawa Y, Hernandez-Benitez R, Wu J, Zhu J, Kim EJ et al. In vivo genome editing via CRISPR/Cas9 mediated homology-independent targeted integration. Nature 2016; 540(7631): 144-149.

7 Lim J-HA, Stafford BK, Nguyen PL, Lien BV, Wang C, Zukor K et al. Neural activity promotes long-distance, target-specific regeneration of adult retinal axons. Nat Neurosci 2016; 19(8): 1073-1084.

8 Goldberg JL, Guido W. Report on the National Eye Institute Audacious Goals Initiative: Regenerating the Optic Nerve. Invest Ophthalmol Vis Sci 2016; 57(3): 1271-1275.

9 Barber A, Farmer K, Martin KR, Smith PD. Retinal regeneration mechanisms linked to multiple cancer molecules: a therapeutic conundrum. Prog Retin Eye Res 2016; e-pub ahead of print 30 August 2016; doi:10.1016/j. preteyeres.2016.08.003.

10 Burns TC, Verfaillie CM. From mice to mind: Strategies and progress in translating neuroregeneration. Eur J Pharmacol 2015; 759: 90-100.

11 Vorwerk CK, Lipton SA, Zurakowski D, Hyman BT, Sabel BA, Dreyer EB. Chronic low-dose glutamate is toxic to retinal ganglion cells: toxicity blocked by memantine. Invest Ophthalmol Vis Sci 1996; 37(8): 1618-1624.

12 Chaudhary P, Ahmed F, Sharma SC. MK801-a neuroprotectant in rat hypertensive eyes. Brain Res 1998; 792(1): 154-158.

13 Russo R, Cavaliere F, Berliocchi L, Nucci C, Gliozzi M, Mazzei $C$ et al. Modulation of pro-survival and deathassociated pathways under retinal ischemia/reperfusion: effects of NMDA receptor blockade. J Neurochem 2008; 107(5): 1347-1357.

14 Kim TW, Kim DM, Park KH, Kim H. Neuroprotective effect of memantine in a rabbit model of optic nerve ischemia. Korean J Ophthalmol 2002; 16(1): 1-7.

15 Geyer O, Almog J, Lupu-Meiri M, Lazar M, Oron Y. Nitric oxide synthase inhibitors protect rat retina against ischemic injury. FEBS Lett 1995; 374(3): 399-402.

16 Neufeld AH, Sawada A, Becker B. Inhibition of nitric-oxide synthase 2 by aminoguanidine provides neuroprotection of retinal ganglion cells in a rat model of chronic glaucoma. Proc Natl Acad Sci USA 1999; 96(17): 9944-9948.

17 Howell GR, MacNicoll KH, Braine CE, Soto I, Macalinao DG, Sousa GL et al. Combinatorial targeting of early pathways profoundly inhibits neurodegeneration in a mouse model of glaucoma. Neurobiol Dis 2014; 71: 44-52.

18 Rosenthal R, Fromm M. Endothelin antagonism as an active principle for glaucoma therapy. Br J Pharmacol 2011; 162(4): 806-816.

19 Mozaffarieh M, Grieshaber MC, Orgül S, Flammer J. The potential value of natural antioxidative treatment in glaucoma. Surv Ophthalmol 2008; 53(5): 479-505.

20 Cheung ZH, So K-F, Lu Q, Yip HK, Wu W, Shan JJ et al. Enhanced survival and regeneration of axotomized retinal ganglion cells by a mixture of herbal extracts. J Neurotrauma 2002; 19(3): 369-378.

21 Kim S-Y, Kwak J-S, Shin J-P, Lee S-H. The protection of the retina from ischemic injury by the free radical scavenger $\mathrm{EGb}$ 
761 and Zinc in the Cat Retina. Ophthalmologica 1998; 212(4): 268-274.

22 Dilsiz N, Sahaboglu A, Yıldiz MZ, Reichenbach A. Protective effects of various antioxidants during ischemia-reperfusion in the rat retina. Graefes Arch Clin Exp Ophthalmol 2006; 244(5): 627-633.

23 Aydemir O, Nazıroğlu M, Çelebi S, Yılmaz T, Kükner AŞ. Antioxidant effects of alpha-, gamma- and succinatetocopherols in guinea pig retina during ischemia-reperfusion injury. Pathophysiology 2004; 11(3): 167-171.

24 Gregory MS, Hackett CG, Abernathy EF, Lee KS, Saff RR, Hohlbaum AM et al. Opposing roles for membrane bound and soluble Fas ligand in glaucoma-associated retinal ganglion cell death. PLoS One 2011; 6(3): e17659.

25 Gregory-Ksander MS, Fei F, Marshak-Rothstein A, Ksander B, Krishnan A. Soluble Fas ligand provides long-term protection in a chronic mouse model of glaucoma by inhibiting glial activation, inflammation, and apoptosis. Invest Ophthalmol Vis Sci 2016; 57: 12.

26 Woldemussie E, Ruiz G, Wijono M, Wheeler LA. Neuroprotection of retinal ganglion cells by brimonidine in rats with laser-induced chronic ocular hypertension. Invest Ophthalmol Vis Sci 2001; 42(12): 2849-2855.

27 Hernández M, Urcola JH, Vecino E. Retinal ganglion cell neuroprotection in a rat model of glaucoma following brimonidine, latanoprost or combined treatments. Exp Eye Res 2008; 86(5): 798-806.

28 Gao H, Qiao X, Cantor LB, WuDunn D. Upregulation of brain-derived neurotrophic factor expression by brimonidine in rat retinal ganglion cells. Arch Ophthalmol 2002; 120(6): 797-803.

29 Lai RK, Chun T, Hasson D, Lee S, Mehrbod F, Wheeler L. Alpha-2 adrenoceptor agonist protects retinal function after acute retinal ischemic injury in the rat. Vis Neurosci 2002; 19(2): 175-185.

30 Wheeler LA, Lai R, WoldeMussie E. From the lab to the clinic: activation of an alpha-2 agonist pathway is neuroprotective in models of retinal and optic nerve injury. Eur J Ophthalmol 1999; 9(Suppl. 1): S17-S21.

31 Dong CJ, Guo Y, Agey P, Wheeler L, Hare WA. Alpha2 adrenergic modulation of NMDA receptor function as a major mechanism of RGC protection in experimental glaucoma and retinal excitotoxicity. Invest Ophthalmol Vis Sci 2008; 49(10): 4515-4522.

32 Krupin T, Liebmann JM, Greenfield DS, Ritch R, Gardiner S. A randomized trial of brimonidine versus timolol in preserving visual function: Results from the low-pressure glaucoma treatment study. Am J Ophthalmol 2011; 151(4): 671-681.

33 Kent AR, Nussdorf JD, David R, Tyson F, Small D, Fellows D. Vitreous concentration of topically applied brimonidine tartrate 0.2\%. Ophthalmology 2001; 108(4): 784-787.

34 Burke J, Schwartz M. Preclinical evaluation of brimonidine. Surv Ophthalmol 1996; 41: S9-18.

35 Hare WA, WoldeMussie E, Lai RK, Ton H, Ruiz G, Chun T et al. Efficacy and safety of memantine treatment for reduction of changes associated with experimental glaucoma in monkey, I: functional measures. Invest Ophthalmol Vis Sci 2004; 45(8): 2625.

36 Allergan. Memantine in Patients With Chronic Glaucoma. In: ClinicalTrials.gov [Internet]. Bethesda, MD: National Library of Medicine (USA). 2000- [accessed on 25 September 2016]. Available at http://clinicaltrials.gov/show/. NCT00141882 NLM Identifier: NCT00141882.
37 Allergan. Memantine in Patients with Chronic Glaucoma. In: ClinicalTrials.gov [Internet]. Bethesda, MD: National Library of Medicine (USA). 2000- [accessed on 25 September 2016]. Available at: https:// clinicaltrials.gov/show/NCT00168350. NLM Identifier: NCT00168350.

38 Garway-Heath DF, Crabb DP, Bunce C, Lascaratos G, Amalfitano $\mathrm{F}$, Anand $\mathrm{N}$ et al. Latanoprost for open-angle glaucoma (UKGTS): A randomised, multicentre, placebocontrolled trial. Lancet 2015; 385(9975): 1295-1304.

39 Johnson TV, Bull ND, Hunt DP, Marina N, Tomarev SI, Martin KR. Neuroprotective effects of intravitreal mesenchymal stem cell transplantation in experimental glaucoma. Invest Ophthalmol Vis Sci 2010; 51(4): 2051-2059.

40 Emre E, Yüksel N, Duruksu G, Pirhan D, Subaşi C, Erman G et al. Neuroprotective effects of intravitreally transplanted adipose tissue and bone marrow-derived mesenchymal stem cells in an experimental ocular hypertension model. Cytotherapy 2015; 17(5): 543-559.

41 Hu Y, Tan HB, Wang XM, Rong H, Cui HP, Cui H. Bone marrow mesenchymal stem cells protect against retinal ganglion cell loss in aged rats with glaucoma. Clin Interv Aging 2013; 8: 1467-1470.

42 Yu S, Tanabe T, Dezawa M, Ishikawa H, Yoshimura N. Effects of bone marrow stromal cell injection in an experimental glaucoma model. Biochem Biophys Res Commun 2006; 344(4): 1071-1079.

43 Johnson TV, Dekorver NW, Levasseur VA, Osborne A, Tassoni A, Lorber B et al. Identification of retinal ganglion cell neuroprotection conferred by platelet-derived growth factor through analysis of the mesenchymal stem cell secretome. Brain 2014; 137(2): 503-519.

44 Tassoni A, Gutteridge A, Barber AC, Osborne A, Martin KR. Molecular Mechanisms Mediating Retinal Reactive Gliosis Following Bone Marrow Mesenchymal Stem Cell Transplantation. Stem Cells 2015; 33(10): 3006-3016.

45 Jin M, Kim JH, Jang E, Lee YM, Soo Han H, Woo DK et al. Lipocalin-2 deficiency attenuates neuroinflammation and brain injury after transient middle cerebral artery occlusion in mice. J Cereb Blood Flow Metab 2014; 34(8): 1306-1314.

46 Lee S, Kim JH, Kim JH, Seo JW, Han HS, Lee WH et al. Lipocalin-2 is a chemokine inducer in the central nervous system: Role of chemokine ligand 10 (CXCL10) in lipocalin2-induced cell migration. J Biol Chem 2011; 286(51): $43855-43870$

47 Tzameret A, Sher I, Belkin M, Treves AJ, Meir A, Nagler A et al. Transplantation of human bone marrow mesenchymal stem cells as a thin subretinal layer ameliorates retinal degeneration in a rat model of retinal dystrophy. Exp Eye Res 2014; 118: 135-144.

48 Kim JY, You YS, Kim SH, Kwon OW. Epiretinal Membrane Formation After Intravitreal Autologous Stem Cell Implantation In A Retinitis Pigmentosa Patient. Retin Cases Brief Rep 2016; e-pub ahead of print 11 May 2016 doi:10.1097/ICB.0000000000000327.

49 Dominici M, Le Blanc K, Mueller I, Slaper-Cortenbach I, Marini F, Krause D et al. Minimal criteria for defining multipotent mesenchymal stromal cells. The International Society for Cellular Therapy position statement. Cytotherapy 2006; 8(4): 315-317.

50 University of Sao Paulo. Intravitreal Mesenchymal Stem Cell Transplantation in Advanced Glaucoma. In: ClinicalTrials.gov [Internet]. Bethesda, MD: National Library of Medicine (USA). 2000- [accessed on 26 September 2016]. Available at 
http:/ / clinicaltrials.gov/show/NCT02330978. NLM Identifier: NCT02330978.

51 Retina Associates of South Florida. Stem Cell Ophthalmology Treatment Study (SCOTS). In: ClinicalTrials.gov [Internet]. Bethesda, MD: National Library of Medicine (USA). 2000[accessed on 26 September 2016]. Available at http:// clinicaltrials.gov/show/NCT01920867. NLM Identifier: NCT01920867.

52 Central Clinical Hospital with Outpatient Health Center of Business Administration for the President of Russian Federation. Effectiveness and Safety of Adipose-Derived Regenerative Cells for Treatment of Glaucomatous Neurodegeneration. In: ClinicalTrials.gov [Internet]. Bethesda, MD: National Library of Medicine (USA). 2000- [accessed on 26 September 2016]. Available at http://clinicaltrials.gov/ show/NCT02144103. NLM Identifier: NCT02144103.

53 Bainbridge JWB, Mehat MS, Sundaram V, Robbie SJ, Barker SE, Ripamonti $C$ et al. Long-term effect of gene therapy on Leber's congenital amaurosis. N Engl J Med 2015; 372(20): 1887-1897.

54 Edwards TL, Jolly JK, Groppe M, Barnard AR, Cottriall CL, Tolmachova $\mathrm{T}$ et al. Visual acuity after retinal gene therapy for choroideremia. N Engl J Med 2016; 374(20): 1996-1998.

55 Gensight Biologics. Safety Evaluation of Gene Therapy in Leber Hereditary Optic Neuropathy (LHON) Patients. In: ClinicalTrials.gov [Internet]. Bethesda, MD: National Library of Medicine (USA). 2000- [accessed on 26 September 2016].
Available at https:/ / clinicaltrials.gov/show/NCT02064569. NLM Identifier: NCT02064569.

56 Wan X, Pei H, Zhao M, Yang S, Hu W, He H et al. Efficacy and Safety of rAAV2-ND4 Treatment for Leber's Hereditary Optic Neuropathy. Sci Rep 2016; 6: 21587.

57 Gensight Biologics. Efficacy Study of GS010 for the Treatment of Vision Loss up to 6 Months From Onset in LHON Due to the ND4 Mutation (RESCUE). In: ClinicalTrials.gov [Internet]. Bethesda, MD: National Library of Medicine (USA). 2000- [accessed on 26 September 2016]. Available at https:/ / clinicaltrials.gov/show/NCT02652767. NLM Identifier: NCT02652767.

58 GenSight Biologics. Efficacy Study of GS010 for Treatment of Vision Loss From 7 Months to 1 Year From Onset in LHON Due to the ND4 Mutation (REVERSE). In: ClinicalTrials.gov [Internet]. Bethesda, MD: National Library of Medicine (USA). 2000- [accessed on 26 September 2016]. Available at https://clinicaltrials.gov/show/NCT02652780. NLM Identifier: NCT02652780.

59 Martin KR, Quigley HA, Zack DJ, Levkovitch-Verbin H, Kielczewski J, Valenta D et al. Gene therapy with brainderived neurotrophic factor as a protection: retinal ganglion cells in a rat glaucoma model. Invest Ophthalmol Vis Sci 2003; 44(10): 4357-4365.

60 Pease ME, Zack DJ, Berlinicke C, Bloom K, Cone F, Wang Y et al. Effect of CNTF on retinal ganglion cell survival in experimental glaucoma. Invest Ophthalmol Vis Sci 2009; 50(5): 2194-2200. 